\title{
EFFECTS OF A THEORY-BASED AUDIO HIV/AIDS INTERVENTION FOR ILLITERATE RURAL FEMALES IN AMHARA, ETHIOPIA
}

\author{
Gebeyehu W. Bogale, Henk Boer, and Erwin R. Seydel
}

\begin{abstract}
In Ethiopia the level of illiteracy in rural areas is very high. In this study, we investigated the effects of an audio HIV/AIDS prevention intervention targeted at rural illiterate females. In the intervention we used social-oriented presentation formats, such as discussion between similar females and role-play. In a pretest and posttest experimental study with an intervention group $(n=210)$ and control group $(n=210)$, we investigated the effects on HIV/AIDS knowledge and social cognitions. The intervention led to significant and relevant increases in HIV/AIDS knowledge, self-efficacy, perceived vulnerability to HIV/AIDS infection, response efficacy of condoms and condom use intention. In the intervention group, self-efficacy at posttest was the main determinant of condom use intention, with also a significant contribution of vulnerability. We conclude that audio HIV/AIDS prevention interventions can play an important role in empowering rural illiterate females in the prevention of HIV/AIDS.
\end{abstract}

The HIV/AIDS epidemic is a major public health concern in Ethiopia (Central Statistical Agency, 2006). The estimated HIV prevalence rate for adults aged 15-49 years is $2.1 \%$ (UNAIDS 2008), with large differences between urban and rural areas (HIV/AIDS Prevention and Control Office, 2006; Hong, Mishra, \& Govindasamy, 2008; Kloos, Haile-Mariam \& Lindtjørn, 2007) and between levels of educational attainment (Bradley et al., 2007). For urban females, the estimated HIV prevalence rate is $7.7 \%$, and for urban males $2.4 \%$; for rural females, the estimation is $0.6 \%$, and for rural males $0.7 \%$ (Central Statistical Agency, 2006). In Ethiopia, 85\% of the population lives in rural areas. Studies indicate that HIV/AIDS is spreading from urban to rural areas (Shabir \& Larson, 1995; Hiladik et al., 2006). HIV/AIDS in ru-

Gebeyehu W. Bogale is with the Educational Media Agency, Addis Ababa, Ethiopia, and the Department of Psychology and Communication of Health and Risk, University of Twente, Enschede, Netherlands. Henk Boer and Erwin R. Seydel are with the Department of Psychology and Communication of Health and Risk, University of Twente, Enschede, Netherlands.

This study was financially supported by an educational grant to the first author by the Netherlands Fellowship Programmes of Nuffic, the Netherlands organization for international cooperation in higher education. The authors thank Ato Demissew Bekele, general manager of Educational Media Agency, Addis Ababa for facilitating the scholarship. The authors thank the radio program producers of the Educational Media Center in Debre Markos, Ethiopia, for producing the audio HIV/AIDS prevention messages. They thank Alemneh Yitayew, HIV/AIDS prevention secretariat officer in Dejen, Amhara, Ethiopia, and the data collectors for their assistance during the field research.

Address correspondence to Henk Boer, Department of Psychology and Communication of Health and Risk, University of Twente, P.O. Box 217, 7500 AE Enschede, Netherlands; e-mail: H.Boer@utwente.nl 
ral areas may be underreported. According to the HIV/AIDS Prevention and Control Office (2006), a large proportion of rural patients seek treatment from traditional healers and buy medicines from pharmacist and marketplaces.

As in many parts of Africa, females in Ethiopia are at higher risk of HIV infection (Central Statistical Agency, 2006; Gregson et al., 2002). This higher risk for HIV infection is partly related to biological factors and the use of unhygienic, harmful traditional practices, such as tattooing, facial scarification, ear perforation, and female genital mutilation. Also, many females in Ethiopia face cultural and social disadvantages, such as early marriage and subservience to males (Clark, Bruce $\&$ Dude, 2006; Pathfinder International, 2006). This limits females in their ability to discuss and negotiate about sexual matters with their sexual partners (Boer \& Mashamba, 2007; Kim \& Watts, 2005; Phetla et al., 2008; Shefer et al., 2008).

In rural Ethiopia the level of illiteracy is high. According to statistics, $78 \%$ of rural females cannot read and write at all; $8 \%$ can read only part of a sentence (Central Statistical Agency, 2006). Given the high level of illiteracy in rural areas, audio interventions can be an effective and cheap channel for HIV/AIDS prevention education. Usually these audio interventions have been made in the form of radio campaigns, which were transmitted to target audiences on regular times (Agha, 2003; Farr, Witte, Jarato, \& Menard, 2005; Vaughan \& Rogers, 2000; Vaughan, Regis, $\&$ St. Catherine, 2000; Karlyn, 2001). However, there are a number of limitations in the use of radio campaigns to reach rural females in Ethiopia. First, most rural females are farmers, who work in the field from dawn to dusk, and most of them have no radio in the field. Second, the mountainous area of Ethiopia limits the reach of radio transmitters, and in many so-called pocket areas no radio signals can be received. To reach rural females with HIV/AIDS prevention education, portable audiocassette players, with rechargeable batteries, seem to be more appropriate. These portable audiocassette players can be used by health care workers (e.g. those who work in remote health posts). Also, communities can use the audio cassettes to disseminate HIV/AIDS prevention education, either in special listening groups or on other occasions, when the members of the community come together, such as on church days or festive days.

To be effective, these audio messages have to focus on the psychosocial determinants that are relevant to promote HIV/AIDS prevention behavior (Aarø et al., 2005; Fishbein, 2000; Hornik \& Yanovitzky, 2003). The theory of planned behavior (Ajzen, 1991) has been widely applied to explain condom use behavior in Africa (Boer \& Mashamba, 2007; Bogale, Boer, \& Seydel, 2010a; Bryan, Kagee, \& Broaddus, 2006; Giles, Liddell, \& Bydawell, 2005; Groenenboom, Van Weert, \& Van den Putte, 2009; Jemmott et al., 2007; Molla, Nordrehaug Åstrøm, \& Brehane, 2007; Taffa, Klepp, Sundby, \& Bjune, 2002). According to the theory of planned behavior, condom use is primarily determined by the intention to use condoms. Intention is a function of three determinants: attitude, social norms, and self-efficacy. Attitude reflects the beliefs about the expected positive and negative consequences of using condoms. Perceived social norms are the expectations of the individual about the opinions of important others, such as family, peers, and other community members, about the appropriateness of using condoms. Self-efficacy is the expectation of the individual to perform the required behavior. According to protection motivation theory, perceived vulnerability and response efficacy are also important in promoting HIV/AIDS preventive behavior (Norman, Boer, \& Seydel, 2005). Studies indicate that perceived vulnerability to HIV/AIDS infection among females in Ethiopia is significantly related to intended and actual condom use (Bogale et al., 2010a; Witte, 
Girma, \& Girgre, 2003). Response efficacy is the belief that condom use is effective to avoid HIV/AIDS infection.

For effective HIV/AIDS prevention communication, both the content and the format of the communication is important. Given the oral tradition and the collectivist culture in many parts of Ethiopia, oral narratives are likely to promote the effectiveness of HIV/AIDS prevention education (Moyer-Gusé, 2008; Panford, Nyaney, Amoah, \& Aidoo, 2001). Usually oral narratives consist of a number of episodes and use different presentation formats, such as discussion, role-play, testimonials, and interviews with experts, such as doctors and nurses (Bogale, Boer, \& Seydel, 2010b).

In this study, we investigated the effectiveness of audio messages with narratives on HIV/AIDS prevention for illiterate rural females in Ethiopia. The messages were adapted to the cultural context of the rural females and used different presentation formats, such as narratives, poems, and discussion and role-play between females who were similar to the target audience. We assessed the impact of the audio messages on HIV/AIDS-related knowledge and social cognitions from the theory of planned behavior and protection motivation theory. We used a quasi-experimental pretest/posttest design, with an experimental group that listened to HIV/AIDS audio messages and a control group that listened to messages on general hygienic behavior.

\section{METHODS}

\section{STUDY DESIGN}

The quasi-experimental study was performed in two communities, which were randomly assigned to the experimental and the control condition. In accordance with the regulations in Ethiopia, the research was approved by the authorities and local community leaders. We selected at random 210 females, aged between 15 and 38 years, from one community (sub-kebele) in the kebele (ward and smallest administrative unit) of Borebor Sencha (near Dejen in Amhara, 250 kilometers northwest of Addis Ababa, Ethiopia), and these females participated in the experimental group. We selected at random 210 females, comparable in age, from another sub-kebele to participate in the control group. To avoid cross-contamination, the control community was about 5 kilometers from the experimental community, which is quite a distance, because in this area the only means of transportation is by foot. Prior to the research, informed consent was obtained from the participants themselves and, if applicable, according to rural culture in Ethiopia, from their spouse and parents. Participants were assured that their participation was voluntary and that their responses were treated confidentially. The Dejen Woreda Administrative Office, the Woreda Women's Affaires Office, the Woreda HIV/AIDS Office, and the health center were informed about the study and their permission was obtained.

Both the experimental group and the control group completed the pretest. After the pretest, the females in the experimental group listened to the audio HIV/AIDS prevention messages on 3 consecutive days in the local school. The duration of each message was about 15 minutes. The females in the control group listened to messages about personal hygiene to avoid infection with ascaris (roundworm); Entamoeba bystolitica, which causes dysenteric disease; and tapeworm, also on 3 consecutive days but in a different local school. After listening, all females participated in the posttest. After the posttest, the females in the control group were given a 45 minutes 
presentation of the three episodes on HIV/AIDS prevention and the females in the experimental group were given a 45 minutes presentation on personal hygiene and how to avoid ascaris, Entamoeba hystolitica, and tapeworm infections.

\section{AUDIO HIV/AIDS EDUCATION}

We designed three audio episodes on HIV/AIDS prevention in the form of radio programs, which were played on audiocassette recorders in listening groups. The listening groups were chaired by the head woman, a female community leader. After listening, there was an opportunity for discussion and posing questions. We briefed local radio producers on specific contents and we used a wide variety of presentation formats, such as interview with a doctor, a nurse, and community leader and narratives, role-play, and discussion between females. The episodes explained what HIV/ AIDS is and how HIV/AIDS can be transmitted by unprotected sexual intercourse. The episodes provided information on the prevention of transmission by the use of condoms and also discussed about abstinence and faithfulness. The episodes also addressed myths about HIV/AIDS transmission. The results of a pretest and a detailed description of the episodes can be found in Bogale et al. (2010b).

\section{CONTROL INTERVENTION}

The control intervention (non HIV focused) comprised three episodes and focused on personal hygiene and the avoidance of eating raw meat. In rural Ethiopia people eat with their hands and washing hands with soap before eating is essential to avoid infection with ascaris (roundworm) and amoeba (Entamoeba hystolitica). Also, eating raw meat, mostly beef, is quite popular in rural Ethiopia on festive days, and it bears the risk of infection with tapeworm. These communicable diseases were chosen for the messages in the control group, because they are neglected tropical diseases, which are caused by lack of sanitation, unhygienic behavior, and poor eating habits, that can be prevented (Awole, Gebre-Selassie, Kassa, \& Kibru, 2003; Mengistu, Gebre-Selassie, \& Kassa, 2007; Poopati \& Abidha, 2008).

\section{MEASURES}

To collect the data, we used a structured questionnaire. The questionnaire was prepared in English and translated from English into Amharic by the first author. Four native speakers of Amharic checked the translation for appropriateness of the language to rural females. HIV/AIDS knowledge was assessed with 13 items. Participants were asked to give right/wrong answers to a list of items related to the transmission and prevention of HIV/AIDS (e.g., "The main cause of HIV/AIDS transmission is unsafe sexual intercourse"; "HIV only affects prostitutes, divorced or widowed"; "Consistent use of condoms means using condoms from the beginning to the end of each sexual encounter"). Initially, the items had 3-point response options (true, false, I do not know), which were dichotomized into correct $(=1)$ and incorrect $(=0)$ in the data analysis. We used the sum score, ranging from 0 to 13 to represent HIV/AIDS knowledge (Cronbach's $\alpha=.87$ ). All social cognitions were assessed with 5-point Likert-items ( $1=$ completely disagree, $5=$ completely agree $)$. Attitude to condoms was measured with three items, which were recoded such that higher score represents a more positive attitude (Cronbach's $\alpha=.64$ ). An example of an attitude item is "Using condoms will make sex less enjoyable." Social norm was assessed by asking the normative beliefs of mother, sister, and friends about the importance of using condoms during sexual intercourse. An example of an item is "My friends think that using condom during sexual intercourse is important" (Cronbach's $\alpha=.89$ ). Within 
the theory of planned behavior, perceptions of control can be assessed as perceived behavioral control or as self-efficacy, two concepts that are closely related (Ajzen, 2002). In this study, we measured perceptions of control as self-efficacy. Self-efficacy was measured with four items (Cronbach's $\alpha=.85$ ). Examples of self-efficacy items include "I am able to talk to my partner/husband about condom use during sexual intercourse" and "I am confident buying condoms from the shops while being seen by others." Response efficacy was measured with three items (Cronbach's $\alpha=.75$ ). An example of response efficacy item is: "Using condoms will protect me against being infected with HIV." Vulnerability to HIV infection was measured with one item: "If I do not use condoms, I run a high risk of HIV/AIDS." Intention to use condom was measured with a three item scale (Cronbach's $\alpha=.79$ ). An example of an intention item is: "In the future I will always use condoms." We assessed sexual activity (1 = yes, $2=$ no) and measured actual condom use with a single item on how often they did use condoms when having sex ( $1=$ never, $2=$ sometimes, $3=$ mostly, $4=$ always $)$. We further assessed marital status $(1=$ unmarried, $2=$ married, $3=$ divorced, $4=$ widowed) and age. Literacy level was assessed by asking to what extent participants could read and write. Those who indicated they cannot read and cannot write were classified as illiterate. Those who could read and write a little (e.g., small texts) were classified as low literate. Those who could read and write quite well (e.g., a paper) were classified medium literate. Those who did not have problems in reading and writing were classified as literate.

\section{PROCEDURE}

Because people in rural Ethiopia are not inclined to tell their opinions to someone they do not know, we used local female data collectors to collect the data. The data collectors read the items aloud and wrote down the responses. The female data collectors were recruited from the same localities in cooperation with the Woreda (district) HIV prevention coordinator. The data collectors were trained to administer the questionnaire in nonjudgmental manner. Separately, the completion of the pretest and the posttest took on average $2 \frac{1}{2}$ hours for each female.

\section{STATISTICAL ANALYSIS}

We calculated descriptive statistics on demographic variables and used chisquare analysis to identify significant differences between the intervention group and control group. On the pretest data, we used $t$ tests to identify significant differences in HIV/AIDS knowledge and social cognitive variables between the intervention and the control group. At posttest, we used multivariate analysis of variance with as covariates literacy level, religion, pretest HIV/AIDS knowledge and pretest scores on social cognitive variables to identify significant differences between the intervention group and the control group. Within the intervention group, paired sample $t$ tests were used to identify increases in HIV/AIDS knowledge and scores on social cognitive variables between the pretest and the posttest. To identify the predictors of condom use intention at posttest, we used multiple regression analyses, separately for the intervention group and the control group.

\section{RESULTS}

A total of 420 females were interviewed at baseline. Of those, 210 participated in the HIV/AIDS prevention intervention and 210 participated in the control intervention. 
TABLE 1. Characteristics of the Intervention and Control Group

\begin{tabular}{|c|c|c|c|}
\hline & $\begin{array}{c}\text { Intervention Group }(\mathrm{N}= \\
210) \mathrm{n}(\%)\end{array}$ & $\begin{array}{c}\text { Control Group }(\mathrm{N}=207) \\
\mathrm{n}(\%)\end{array}$ & 2 \\
\hline Literacy level & & & $15.5^{* * *}$ \\
\hline Illiterate & $130(66)$ & $139(68)$ & \\
\hline Low literate & $41(20)$ & $40(19)$ & \\
\hline Medium literate & $9(4)$ & $9(5)$ & \\
\hline Literate & $20(10)$ & $19(8)$ & \\
\hline Age & & & 5.7 \\
\hline $15-20$ & $45(21)$ & $53(25)$ & \\
\hline $21-25$ & $48(23)$ & $60(29)$ & \\
\hline $26-30$ & $82(39)$ & $59(28)$ & \\
\hline $31-38$ & $36(17)$ & $37(18)$ & \\
\hline Marital status & & & 2.7 \\
\hline Unmarried & $9(4)$ & $15(7)$ & \\
\hline Married & $144(69)$ & $141(69)$ & \\
\hline Divorced & $47(23)$ & $46(22)$ & \\
\hline Widowed & $9(4)$ & $5(2)$ & \\
\hline Religion & & & $22.1 * * *$ \\
\hline Ethiopian Orthodox & $178(85)$ & $200(98)$ & \\
\hline Muslim & $31(15)$ & $4(2)$ & \\
\hline \multicolumn{4}{|l|}{ Sexually active } \\
\hline Yes & $200(96)$ & 206 (99) & \\
\hline No & $9(4)$ & $3(1)$ & 3.1 \\
\hline Condom use & & 5.6 & \\
\hline Never & $187(90)$ & $96(94)$ & \\
\hline Sometimes & $13(6)$ & $10(5)$ & \\
\hline Mostly & $3(1)$ & $0(0)$ & \\
\hline Always & $6(3)$ & $2(1)$ & \\
\hline
\end{tabular}

$*$ * $<.001$

All participants in the pretest also participated in the posttest. Sample characteristics are displayed in Table 1.

Most participants were illiterate and low-literate females, with more $(85 \%)$ illiterate and low literate females in the control group, in comparison to the experimental group $(78 \%)$. Participant ages ranged from 15 to 38 years, with an average of 26 years $(S D=5)$, with no significant difference between groups. Most participants were married or divorced, with no significant difference between groups. In both groups, the majority of the participants were Ethiopian Orthodox Christians, but in the intervention group relatively more Muslim females participated. Almost all females were sexually active, with no significant difference between the groups. Actual condom use was very low with more than $90 \%$ of the females never using condoms, and no significant difference between the groups.

\section{HIV/AIDS KNOWLEDGE AND SOCIAL COGNITION AT BASELINE}

At baseline, the intervention group had significantly better HIV/AIDS knowledge $(M=7.50, S D=2.8)$ than did the control group $(M=6.07, S D=3.3), t(418)$ $=4.89, p<.01$ (Table 2 ). Social norm to use condoms was significantly lower in the intervention group $(M=2.97, S D=1.0)$ than in the control group $(M=3.18, S D=$ $1.0), t(417)=-2.13, p<.05$. The mean scores on the other cognitive variables were not significantly different between the intervention group and the control group.

Given the differences between the intervention group and the control group on literacy level, religion, preexisting HIV/AIDS knowledge and social norms to condom use, in the posttest we calculated the differences between the control group and 
TABLE 2. Mean Scores (SD) at Pretest and Posttest of the Intervention Group and the Control Group.

\begin{tabular}{lcccc}
\hline & \multicolumn{2}{c}{ Pretest } & \multicolumn{2}{c}{ Posttest } \\
\cline { 2 - 5 } & Control & Intervention & Control & Intervention \\
\hline HIV/AIDS knowledge & $6.07(3.3)$ & $7.50(2.8)^{* * *}$ & $7.55(3.1)$ & $9.98(1.6)^{* * *}$ \\
Attitude & $2.84(1.0)$ & $2.93(.9)$ & $3.03(.9)$ & $3.07(1.0)$ \\
Social norm & $3.18(1.0)$ & $2.97(1.0)^{*}$ & $3.09(.9)$ & $3.25(1.1)^{*}$ \\
Self efficacy & $3.01(1.1)$ & $3.06(1.1)$ & $3.30(1.0)$ & $3.87(.8)^{* * *}$ \\
Response efficacy & $3.55(.9)$ & $3.62(.8)$ & $3.70(.8)$ & $4.23(.6)^{* * *}$ \\
Vulnerability & $3,31(1.3)$ & $3.41(1.2)$ & $3.64(1.0)$ & $4.17(.7)^{* * *}$ \\
Intention & $3.16(1.2)$ & $3.02(1.1)$ & $3.35(1.0)$ & $3.81(.8)^{* * * *}$ \\
\hline
\end{tabular}

$* p<.05 . * p<.01 . . * * * p<.001$.

intervention group, using literacy level, religion, HIV/AIDS knowledge score, and scores on social cognitions in the pretest as covariates.

\section{EFFECTS OF THE AUDIO HIV/AIDS INTERVENTION}

After the intervention, HIV/AIDS knowledge in the intervention group $(M=$ 9.98, $S D=1.6)$ was significantly higher than in the control group $(M=7.55, S D=$ 3.1) $(F(1,411)=55.1, p<.001$. Also within-group analysis showed that among participants in the intervention group HIV/AIDS knowledge at posttest $(M=9.98$, $S D=1.6)$ was significantly higher than at pretest $(M=7.50, S D=2.8), t(210)=$ $12.9, p<.001$. Between the control group and the intervention group no significant differences existed in attitude to condoms, $F(1,411)<1$, ns $)$ and among the intervention group participants also posttest attitude to condoms was not significantly different from pretest attitude to condoms, $t(210)=1.7, p=.09$. At posttest the mean social norm to use condoms in the intervention group $(M=3.25, S D=1.1)$ was significantly higher than in the control group $(M=3.09, S D=.9), F(1,411)$ $=6.3, p<.05$. Also within-group analysis in the intervention group showed a significant increase in perceived social norm to use condoms between the pretest $(M=$ $2.97, S D=1.0)$ and the posttest $(M=3.25, S D=1.1), t(209)=3.6, p<.001$. The intervention had a strong effect on level of self-efficacy. In comparison to the control group $(M=3.3, S D=1.0)$, mean self-efficacy to condom use was significantly higher in the intervention group $(F(1,411)=31.7, p<.001$. Within-group analysis in the intervention group also revealed a strong increase in self-efficacy between the pretest $(M=3.06, S D=1.1)$ and the posttest $(M=3.87, S D=.8), t(209)=10.9, p$ $<.001$. After the intervention, perceived response efficacy of condoms was significantly higher in the intervention group, in comparison to the control group $F(1,411)$ $=46.5, p<.001$ ), and in the intervention group response efficacy of condoms was significantly higher at posttest, in comparison to pretest, $t(209)=9.9, p<.001$. The intervention increased perceived vulnerability to HIV/AIDS infection, as is indicated by significantly higher mean score at posttest in the intervention group, in comparison to the control group, $F(1,411)=26.1, p<001)$, and in comparison to the mean score of the intervention group at pretest, $t(209)=8.0, p<.001$. Intention to use condoms was significantly higher in the intervention group at posttest than in the control group, $F(1,411)=21.4, p<.001)$. Within-group analysis also showed a strong increase in the intention to use to condoms in the intervention group between the pretest and the posttest, $t(209)=10.6, p<.001$.

To get an indication of the improvement of HIV/AIDS knowledge and scores on social cognitive variables, we calculated the increase in percentage in the intervention 
TABLE 3. The Correlations Between HIV/AIDS Knowledge, Social Cognitive Variables and Condom Use Intention at Posttest for the Total Group $(N=210)$.

\begin{tabular}{|c|c|c|c|c|c|c|}
\hline & KNOW & ATT & SOC & EFF & RESP & VUL \\
\hline \multicolumn{7}{|c|}{ HIV/AIDS knowledge (KNOW) } \\
\hline Attitude (ATT) & $.11^{*}$ & & & & & \\
\hline Social norm (SOC) & .05 & $-.31 * * *$ & & & & \\
\hline Self-efficacy (EFF) & $.29 * * *$ & -.05 & $.51^{* * *}$ & & & \\
\hline Response efficacy (RESP) & $.36^{* * *}$ & -.02 & $.36^{* * *}$ & $.58 * * *$ & & \\
\hline Vulnerability (VUL) & $.27 * * *$ & -.05 & $.37^{* * *}$ & $.67 * * *$ & $.60 * *$ & \\
\hline Intention (INT) & $.25 * *$ & .04 & $.34 * * *$ & $.65^{* * *}$ & $.40 * *$ & $.58 * *$ \\
\hline
\end{tabular}

group between the mean scores in the pretest and the mean scores in the posttest. The increase in HIV/AIDS knowledge was 33\% (9.98/7.50), in self-efficacy $26 \%$ (3.87/3.06), in condom use intention 26\% (3.81/3.02), in perceived vulnerability 23 $\%(4.17 / 3.41)$, and in response efficacy $17 \%$ (4.23/3.62). The intervention was less successful in changing perceived social norms with an increase of $9 \%(3.25 / 2.97)$ and attitude with an increase of $5 \%(3.07 / 2.93)$.

\section{HIV/AIDS KNOWLEDGE, SOCIAL COGNITIONS, AND CONDOM USE INTENTION}

Table 3 shows the correlation at posttest between HIV/AIDS knowledge, social cognitions, and condom use intention for the total group.

At posttest, HIV/AIDS knowledge was significantly related to self-efficacy, response efficacy, vulnerability, and condom use intention. Condom use intention was significantly related to social norms, self-efficacy, response efficacy, and perceived vulnerability to HIV/AIDS infection. To disentangle the relative importance of knowledge and social cognitions in the shaping of condom use intention, we performed linear regression analyses separately for the intervention group and the control group.

Table 4 shows in the intervention group intention to use condoms is significantly related to social cognitions, $F(6,203)=41.69, p<.001$, with significant contributions of self-efficacy and vulnerability to HIV/AIDS infection. In the control group, intention is also significantly related to social cognitive variables, $F(6,202)=20.34$, $p<.001$, with significant contributions of self-efficacy and vulnerability. Comparison of the beta values of the intervention group and the control group shows that in the intervention group self-efficacy is a much stronger predictor of condom use intention than in the control group (.62 vs. 35 ). In both groups, vulnerability is about equally important as a predictor of condom use intention.

\section{DISCUSSION}

The aim of this experimental study was to investigate the effects of audio HIV/AIDS prevention messages produced for illiterate rural females. The audio messages focused on the improvement of HIV/AIDS knowledge and on a change in social cognitive variables that are important for HIV/AIDS prevention behavior. After listening to the three episodes, females in the intervention group showed, in comparison with the control group, a significant increase in HIV/AIDS knowledge, perceived higher 
TABLE 4. Linear Regression Analysis of HIV/AIDS Knowledge and Social Cognitive Variables on Condom Use Intention Posttest in the Intervention Group and Control Group

\begin{tabular}{lcc}
\hline & Intervention Group & Control Group \\
\hline HIV/AIDS knowledge & $\beta$ & $\beta$ \\
Condom attitude & -0.03 & 0.09 \\
Condom social norm & 0.06 & 0.09 \\
Condom self-efficacy & -0.03 & 0.11 \\
Response efficacy & $.62^{* *}$ & $.35^{* *}$ \\
Vulnerability & -0.09 & -0.11 \\
& $.25^{* *}$ & $.29 * *$ \\
$R^{2}$ & & 0.38 \\
\hline$* p<.001$. & 0.55 &
\end{tabular}

social norms with regard to condom use and had a higher level of self-efficacy with regard to condom use. Females in the intervention group also had a higher level of response efficacy of condoms as a means to prevent HIV/AIDS infection and they also felt more vulnerable to HIV/AIDS infection. Finally, intention to use condoms was significantly higher in the intervention group than in the control group, after listening to the audio HIV/AIDS prevention messages. Additional within-group analyses showed a significant increase among females in the intervention group between the pretest and the posttest on all variables, except attitude.

After the intervention, the mean HIV/AIDS knowledge score was 9.98, which is about $77 \%$ of the total score. So, after the intervention, the level of HIV/AIDS knowledge was relatively high. The intervention had a relatively strong influence on HIV/AIDS knowledge with an increase of $33 \%$. However, regression analysis indicated that after the intervention HIV/AIDS knowledge was not related to condom use intention in the intervention group. So, HIV/AIDS knowledge is an important prerequisite for behavioral change, but it does not in itself promote condom use intention.

The intervention also had a strong effect on self-efficacy, vulnerability and intention to use condoms, with mean increases of about $25 \%$. Regression analyses showed that after the intervention condom use intention was strongly related to self-efficacy. In the intervention group, self-efficacy was about twice as important as a predictor of condom use intention as in the control group. Also, other studies have shown that among African females self-efficacy is an important determinant of condom use behavior (Boer \& Mashamba, 2007; Groenenboom, Van Weert, \& Van den Putte, 2009; Phetla et al., 2008). This means that the increase in self-efficacy that was achieved by the narrative program was directly related to an increase in condom use intention. Also vulnerability played an important role in the shaping of condom use intention after the intervention. This means that perceptions of vulnerability are directly related to condom use intention. This finding is important, given the current controversy on the role of perceived vulnerability as a determinant of condom use behavior in Africa (Bogale et al., 2010a; Green \& Witte, 2006; Halparin, 2006). The results of this study show that programs that shape accurate perceptions of vulnerability may be effective to promote condom use, although the risk should not be exaggerated (Bogale et al., 2010a). 
In rural Ethiopia, the level of illiteracy is high and it is a major challenge for HIV/AIDS education to reach this target group. Results of this study show that audio interventions, which use different presentation formats, such as interviews with medical experts, an interview with a community leader, and more narrative formats, such as dialogue and discussion between females, are an effective means for improving knowledge and bring about the necessary changes in social cognitions to promote condom use behavior. An important finding in this study was that audio HIV/ AIDS prevention messages, which use narrative format, not only increase knowledge and social cognitions but also strengthen the importance of self-efficacy as a predictor of condom use intention. So, the oral messages had a double effect on intention: The messages increased the relevant social cognitions and the messages made selfefficacy a more important determinant of condom use intention.

The results of this study indicate that culturally relevant messages targeted to rural females may strongly promote condom use intention. The finding that narrative messages, which are culturally relevant, can promote condom use behavior is in accordance with Malan (2009), who pointed out the importance of culturally relevant narratives. To be effective, it is necessary that HIV/AIDS prevention messages for rural females incorporate cultural values and narratives that are appreciated by these special target groups (Bogale et al., 2010b). As in many African countries, in Ethiopia HIV/AIDS prevention messages have been mainly produced in urban areas and broadcasted through radio to the general audience (Farr, Witte, Jarato, \& Menard, 2005; Vaughan \& Rogers, 2000). If oral narrative messages are directly related to the lives of the rural audiences and appreciated by these audiences, these messages are likely to cause transportation into the narrative world (Green \& Brock, 2000), which promotes careful listening and changes in the social cognitions of the target audience. This will lead to a change in their behavior.

In this study, we used social cognitive theories to develop the messages and to evaluate the effectiveness of these messages. The audio messages focused on changing HIV/AIDS knowledge and social cognitions (attitude, social norm, self-efficacy, response efficacy, vulnerability, and condom use intention) in order to promote actual condom use. The results of this study show that social cognitive theories are not only relevant in predicting condom use behavior in Africa (Boer \& Mashamba, 2007; Bryan et al, 2006; Bogale et al., 2010a; Giles et al., 2005; Groenenboom et al., 2009; Jemmott et al., 2007; Molla et al., 2007; Taffa, Klepp, Sundby, \& Bjune, 2002) but can also be used as an effective means for the design, development, and evaluation of HIV/AIDS prevention messages (Aarø et al., 2005; Fishbein, 2000).

There are a few limitations to this study. First, the study focused on condom use intention and we did not assess actual condom use. The main aim of this study was to assess short-term changes in HIV/AIDS knowledge and social cognitions that can be achieved by audio HIV/AIDS prevention messages that were specifically produced for rural illiterate females. Given the effectiveness of these audio messages in improving knowledge and changing social cognitions, future studies should focus on the long-term effects on actual condom use behavior. A meta-analysis across 96 studies has shown that social cognition models, such as the theory of planned behavior, are quite predictive of future behavior and on average explained $28 \%$ of the variance in condom use behavior (Albarracín, Johnson, Fishbein, \& Muellerleile, 2001). A second limitation is that this study only focused on females. Given the gender power imbalance in sexual matters in many parts of Africa (Boer \& Mashamba, 2007; Shefer et al., 2008), it is required to develop specific audio messages targeted at rural 
males. These male audio messages can use the same narrative formats as used in this study.

We can conclude from this study that among illiterate rural females audio HIV/AIDS messages are effective in promoting HIV/AIDS related knowledge and in changing the social cognitions that are important for intended condom use, in particular condom related self-efficacy. This study shows that carefully designed audio messages, that take into account the cultural values of the target group, are an important means to communicate about HIV/AIDS prevention with this often neglected group of rural females that are difficult to reach by traditional HIV/AIDS prevention education. We conclude the audio interventions can play an important role to empower rural illiterate females in the prevention of HIV/AIDS.

\section{REFERENCES}

Aarø, L.E., Flisher, A.J., Kaaya, S., Onya, H., Fuglesang, M., Klepp, K. et al. (2005). Promoting sexual and reproductive health in early adolescence in South Africa and Tanzania: Development of a theory and evidence based intervention programme. Scandinavian Journal of Public Health, 30, 148-160.

Agha, S. (2003).The impact of a mass media campaign on personal risk perceptions, perceived self-efficacy and on other behavioral predictors. AIDS Care, 15, 749-762.

Ajzen, I. (1991). The Theory of Planned Behavior. Organizational Behavior and Human Decision Processes, 50, $179-211$.

Ajzen, I. (2002). Perceived behavioral control, selfefficacy, locus of control, and the theory of planned behavior. Journal of Applied Social Psychology, 4, 665-683.

Albarracín, D., Johnson, B.T., Fishbein, M., \& Muellerleile, P. (2001). Theories of reasoned action and planned behavior as models of condom use: A meta-analysis. Psychological Bulletin, 127, 142-161.

Awole, M., Gebre-Selassie, S., Kassa, T., \& Kibru, G. (2003). Prevalence of intestinal parasites in HIV-infected adult patients in southwestern Ethiopia. Ethiopian Journal of Health Development, 17(1), 71-78.

Boer, H., \& Mashamba, M.T. (2007). Gender power imbalance and differential psychosocial correlates of intended condom use among male and female adolescents from Venda, South Africa. British Journal of Health Psychology, 12, 51-63.

Bogale, G.W., Boer, H., \& Seydel, E.R. (2010a). Condom use among low-literate, rural females in Ethiopia: The role of vulnerability to HIV infection, condom attitude, and selfefficacy. AIDS Care, 22(7), 851-857.

Bogale, G.W., Boer, H., \& Seydel, E.R. (2010b). Reaching the hearts and minds of illiterate women in the Amhara highland of Ethiopia: Development and pretesting of oral
HIV/AIDS prevention messages. Journal of Social Aspects of HIV/AIDS, 7(1), 94-101.

Bradley, H., Bedada, A., Brahmbhatt, H., Kidanu, A., Gillespie, D., \& Tsui, A. (2007). Educational attainment and HIV status among Ethiopian voluntary counseling and testing clients. AIDS and Behavior, 11, 736-742.

Bryan, A., Kagee, A., \& Broaddus, M.R. (2006). Condom use among South African adolescents: Developing and testing theoretical models of intention and behavior. AIDS and Behavior, 10, 387-397.

Central Statistical Agency (2006). Ethiopia Demographic and Health Survey 2005. Addis Ababa, Ethiopia: Central Statistical Agency.

Clark, S., Bruce, J., \& Dude, A. (2006). Protecting young women from HIV/AIDS: The case against child and adolescent marriage. International Family Planning Perspectives, 32 (2), 1-15.

Farr, A.C., Witte, K., Jarato, K., \& Menard, T. (2005). The effectiveness of media use in health education: Evaluation of an HIV/ AIDS radio campaign in Ethiopia. Journal of Health Communication, 10, 225-235.

Fishbein, M. (2000). The role of theory in HIV prevention. AIDS Care, 12, 273-278.

Giles, M., Liddell, C., \& Bydawell, M. (2005). Condom use in African adolescents: The role of individual and group factors. AIDS Care, 17, 729-739.

Green, M.C., \& Brock, T.C. (2000). The role of transportation in the persuasiveness of public narratives. Journal of Personality and Social Psychology, 79(5), 701-721.

Green, E.C., \& Witte, K. (2006). Can fear arousal in public health campaigns contribute to the decline of HIV/AIDS prevalence? Journal of Health Communication, 11, 245-259.

Gregson, S., Nyamukapa, C.A., Garnett, G.P., Mason, P.R., Zhuwau, T. Caraël, M., et al. (2002). Sexual mixing patterns and sexdifferentials and teenage exposure to HIV 
infection in rural Zimbabwe. The Lancet, 359, 1896-1903.

Groenenboom, M., Van Weert, J., \& Van den Putte, B. (2009). Condom use in Tanzania and Zambia: A study on the predictive power of the theory of planned behavior on condom use intention. In L. Lagerwerf, $\mathrm{H}$. Boer, \& H.Wasserman (Eds.), Health communication in southern Africa: Engaging with social and cultural diversity (pp. 1-33). Pretoria, South Africa: UNISA Publishers/ Amsterdam: Rozenberg.

Halparin, D.T. (2006). The controversy over fear arousal in AIDS prevention and lessons from Uganda. Journal of Health Communication, 11, 266-267.

HIV/AIDS Prevention and Control Office. (2006). National guidelines for the management of sexually transmitted infections using the syndromic approach. Addis Ababa, Ethiopia: Federal Ministry of Health.

Hiladik, W., Shabbir, I., Jelaludin, A., Woldu, A., Tsehaynesh, M., \& Tadesse, W. (2006). HIV/AIDS in Ethiopia: where is the epidemic heading? Sexually Transmitted Infections, 82(Suppl.), i32-i35.

Hong, R., Mishra, V., \& Govindasamy, P. (2008). Factors associated with prevalent HIV infections among Ethiopian adults: Further analysis of the 2005 Ethiopia Demographic and Health Survey. Calverton, MD: Macro International Retrieved February 19, 2010, from http://www.measuredhs.com/pubs/ start.cfm? CFID $=2717514 \&$ CFTOKEN $=54$ 348703.

Hornik, R., \& Yanovitzky, I. (2003). Using theory to design evaluations of communication campaigns: The case of the national youth anti-drug media campaign. Communication Theory, 13(2), 204-224.

Jemmott, J.B., Heeren, G.A., Ngwane, Z., Hewitt, N., Jemmott, L.S., Shell, R., et al. (2007). Theory of planned behavior predictors of intention to use condoms among Xhosa adolescents in South Africa. AIDS Care, 19, 677-684.

Karlyn, A.S. (2001). The impact of a targeted radio campaign to prevent STIs and HIV/AIDS in Mozambique. AIDS Education and Prevention, 13(5), 438-451.

Kim, J.C., \& Watts, C.H. (2005). Gaining a foothold: Tackling poverty, gender inequality, and HIV in Africa. British Medical Journal, 331, 769-772.

Kloos, H., Haile-Mariam, D., \& Lindtjørn, B. (2007). The AIDS epidemic in a low-income country: Ethiopia. Human Ecology Review, 14(1), 39-55.

Malan, M. (2009). Edutainment radio programmes: The importance of culturally relevant stories. In L. Lagerwerf, H. Boer, \& H. Wasserman (Eds.), Health commu- nication in southern Africa: Engaging with social and cultural diversity (pp.137-152). Pretoria: UNISA Publishers/Amsterdam, the Netherlands: Rozenberg Publishers.

Mengistu, A., Gebre-Selassie, S., \& Kassa, T. (2007). Prevalence of intestinal parasitic infections among urban dwellers in southwest Ethiopia. Ethiopian Journal of Health Development, 21(1), 12-17.

Molla, M., Nordrehaug Åstrøm, A., \& Brehane,Y. (2007). Applicability of the theory of planned behavior to intended and selfreported condom use in a rural Ethiopian population. AIDS Care, 19(3), 425-431.

Moyer-Gusé, E. (2008). Toward a theory of entertainment persuasion: Explaining the persuasive effects of entertainment-education messages. Communication Theory, 18(3), 407-425.

Norman, P., Boer, H., \& Seydel, E.R. (2005). Protection motivation theory. In M. Conner \& P. Norman (Eds.), Predicting health behavior (pp. 81-126). Maidenhead, Berleshire, England: Open University Press.

Panford, S., Nyaney, M.O., Amoah, S.O., \& Aidoo, N.G. (2001). Using folk media in HIV/ AIDS prevention in rural Ghana. American Journal of Public Health, 91, 1559-1562.

Pathfinder International. (2006). Creating partnerships to prevent early marriage in the Amhara region, Ethiopia. Retrieved February 20, 2010, from http://www. .org//site/ DocSeerver/Pathfinder, Ethiopia report final pdf? docID $=6581$.

Phetla, G., Busza, J., Hargreaves, J.R., Pronyk, P.M., Kim, J.C., Morison, L.A., et al. (2008). "They have opened our mouths": Increasing women's skills and motivations for sexual communication with young people in rural South Africa. AIDS Education and Prevention, 20(6), 504-518.

Poopati, S., \& Abidha, P. (2008). Insight into tropical human infectious diseases: An update. African Journal of Infectious Diseases, 2(1), $1-41$.

Shabir, I., \& Larson, C.P. (1995). Urban to rural routes of HIV infection spread in Ethiopia. Journal of Tropical Medicine and Hygiene, 5, 338-342.

Shefer, T., Crawford, M., Strebel, A., Simbayi, L.C., Dwadwa-Henda, N., Cloete, A. et al. (2008). Gender, power and resistance to change among two communities in the Western Cape, South Africa. Feminism and Psychology, 18(2), 157-182.

Taffa, N., Klepp, K.I., Sundby, J., \& Bjune, G. (2002). Psychosocial determinants of sexual activity and condom use intention among youth in Addis Ababa, Ethiopia. International Journal of STD and AIDS, 13, 714-719. 
UNAIDS. (2008). Ethiopia country situation 2008. Retrieved February 19, 2010, from http://data.unaids.org/pub/FactSheet/2008/ sa08_eth_en.pdf

Vaughan, P.W., \& Rogers, E.M. (2000). A staged model of communication effects: Evidence from an entertainment-education radio soap opera in Tanzania. Journal of Health Communication, 5, 203-227.

Vaughan, P.W., Regis, A., \& St. Catherine, E. (2000). Effects of an entertainment-educa- tion radio soap opera on family planning and HIV prevention in St. Lucia. International Family Planning Perspectives, 26(4), 1-22.

Witte, K., Girma, B., \& Girgre, A. (2003). Addressing underlying mechanisms to HIV/ AIDS preventive behaviors in Ethiopia. International Quarterly of Community Health Education, 21(2), 163-176. 